\title{
Automobile Emission Reduction and Environmental Protection through Use of Green Renewable Fuel
}

\author{
Rajesh Kumar Pandey, A. Rehman, R. M. \\ Sarviya \& Savita Dixit
}

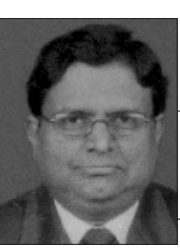

Rajesh K Pandey

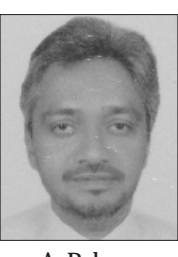

A. Rehman

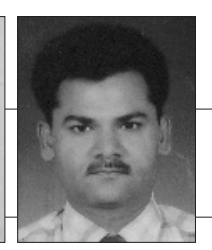

R.M.Sarviya

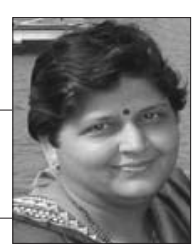

Savita Dixit

Abstract: Fossil fuels are the chief contributors to urban air pollution and major source of green house gases and considered the prime cause behind the global climate change. With the increasing fuel prices, the auto industry forced to make their engines to breathe cleanly and fuel efficiently. Biodiesel is a renewable diesel fuel substitute that can be made by chemically combining any natural oil or fat with an alcohol such as methanol or ethanol. Some of the wellknown liquid biofuel are ethanol for gasoline engines and biodiesel for compression ignition engines or diesel engines. Biodiesel is a renewable and environmental friendly alternative diesel fuel for diesel engine. It can be produced from food grade vegetable oils or edible oils, nonfood grade vegetable oils or inedible oil, animal fats and waste or used vegetable oils, by the transesterification process. Transesterification is a chemical reaction in which vegetable oils and animal fats are reacted with alcohol in the presence of a catalyst. The products of reaction are fatty acid alkyl ester and glycerin, and where the fatty acid alkyl ester known as biodiesel. Biodiesel is an oxygenated fuel containing $10 \%$ to $15 \%$ oxygen by weight. Using biodiesel can help to reduce the world's dependence on fossil fuels and has significant environmental benefits. The reasons for these environmental benefits using biodiesel instead of the conventional diesel fuel reduces exhaust emissions such as the overall life circle of carbon dioxide (CO2), particulate matter (PM), carbon monoxide (CO), sulfur oxides (SOx), volatile organic compounds (VOCs), and unburned hydrocarbons (HC) significantly. Furthermore, since biodiesel can be said a sulfur-free fuel, it has $99 \%$ less SOx emission than the diesel fuel. However, most of the biodiesel produce $10 \%$ to $15 \%$ higher oxides of nitrogen (NOx) when fueling with $100 \%$ biodiesel for a cleaner air and cleaner environment. They are technically competitive with and offer technical advantages compared to petroleum-diesel fuel. Aside from being renewable and biodegradable, biodiesel reduces most emissions while engine performance and fuel economy are nearly the same as the conventional fuel. In this paper author have discussed various merits and de-merits of biodiesel on the environment used as C.I.Engine fuel.

Key words: Biodiesel, CO2 emission, global warming, emission reduction

\section{Introduction}

The use of vegetable oils as diesel fuel is nearly as old as the diesel engine itself. The inventor of the diesel engine, Rudolf Diesel, reportedly used groundnut oil as a fuel for demonstration purposes in $1900 \mathrm{AD}$. Fuel and energy crisis and the concern of society for depleting world's non-renewable resources have initiated various sectors to look for alternative fuels (Pundir 2007). One of the most promising fuel alternatives is vegetable oils and their derivatives. Hundreds of scientific articles and research activities from around the world have been printed on this subject. Oils from karanja, Jatropha, coconut, soybean, sunflower, safflower, peanut, linseed and palm have been used depending on what country they growin abundantly. In the Philippines alone, research activities on the use of vegetable oils as fuel substitute were done as early as the 1970s using coconut oil. In the United States, the primary interest as a biodiesel source is soybean oil, while many European countries are concerned with rapeseed oil, and countries with tropical climate prefer to utilize coconut oil or palm oil. Furthermore, other sources of biodiesel studied animal fat and used fryingoil (Rehman and Singhai 1995). Several problems, however, have caused delay in the widespread use of biodiesel. The first is economics and the second relates to the property of biodiesel. Use of neat vegetable oils cause injector choking, engine deposits, ring sticking and thickening of the engine lubricant (Agarwal 2006). To overcome this problem, various modifications to vegetable oils have been suggested, such as transesterification, micro-emulsion formation and the use of viscosity reducers. Among these, transesterification is considered the most suitable modification because technical properties of esters are nearly similar to those of diesel (Rehman et al 2009c).

The term biodiesel, in general, refers to neat vegetable oils used as diesel fuel as well as neat methyl esters prepared from vegetable oils or animal fats, and even blends of conventional diesel fuel with vegetable oils or methyl esters. Due to problems encountered in the use of neat vegetable oil, biodiesel is now referred to as the mono alkyl esters of long chain fatty acids derived from vegetable oils for use in compression ignition (diesel) engines. Methyl ester is usually made from $80-90 \%$ vegetable oil, $10-20 \%$ alcohol and $0.35-1.5 \%$ catalyst (Rehman et al 2009a).

\section{Biodiesel Conversion from Vegetable Oil}

The process of making biodiesel is called transesterification. It is the transformation of one type of an ester into another type of ester. Transesterification 
chemically breaks the molecule of the raw renewable oil into methyl ester with glycerol as a by-product. Most vegetableoil istriglycerides(TG). Chemically, triglycerides are the triacylglyceryl esters of various fatty acids with glycerol. About $20 \%$ of a vegetable oil molecule is glycerin (Puhan et al.2005). During transesterification, glycerol is removed from the vegetable oil, thus making the oil thick and reducing its viscosity. The most common derivative of triglycerides or fatty acids for fuels is the methyl esters. Methyl esters are formed by the transesterificion of the TG with methanol in the presence of a basic catalyst to give the methyl ester and glycerol shown in Figure 1. Other alcohols have been used to generate esters, like the ethyl, propyl and butyl alcohol. Methanol, however, is the preferred alcohol because it produces a more stable biodiesel reaction, it is less affected by water in the vegetable oil, and the transesterification reaction is faster compared with other alcohols (Rehman et al 2009b).

A typical transesterification procedure follows. A weighed amount of oil is charged into a biodiesel reactor. The catalyst is dissolved in alcohol in a small reactor by vigorous stirring and then added to the oil. Vigorous it contains practically no sulfur and substantially reduces emissions of unburned hydrocarbon (HC), carbon monoxide, sulfates, polycyclic aromatic $\mathrm{HC}(\mathrm{PAH})$ and particulate matter Ramesh et.al 2003.

. It has fuel properties comparable to mineral diesel and because of great similarity; it can be mixed with mineral oil and used in standard diesel engines with minor or no modifications at all. Biodiesel works well with new technologies such as catalysts (which can reduce the soluble fraction of diesel particulates, but not the solid carbon fraction), particulate traps and exhaust gas re-circulation. It can be produced from any kind of oil both vegetable and animal source (Pramanik 2003). Used frying oil can also be used and, therefore, is a promising alternative for waste treatment. Being an agricultural product, all countries have the ability to produce and control this energy source, which is a situation very different from the crude oil business. It can strengthen the economy by creating more jobs and create independence from the imported depleting commodity, petroleum. It can also be used as a way of stimulating and supporting agriculture (Usta 2005).

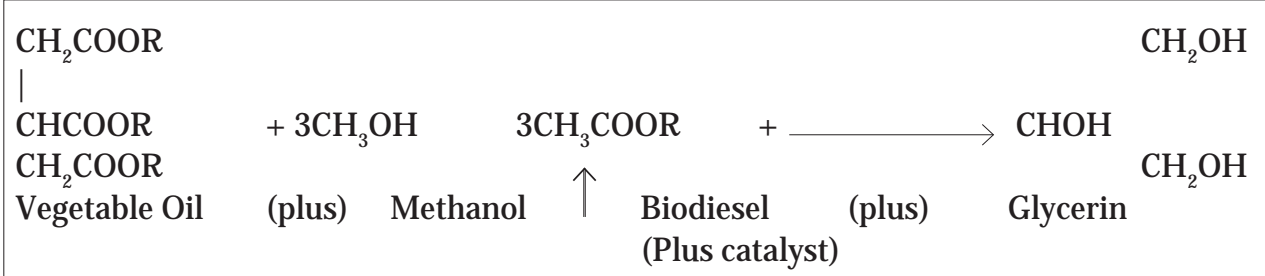

Figure 1. The Transesterification Reaction

stirring of the solution is continued for three hours. A successful reaction produces two liquid phases: the ester found at the upper layer and the crude glycerol found in the lower layer. Phase separation can be observed within 10 minutes after the stirringstops and can becompleted in three to eight hours. After complete settling, the glycerol is drained. The catalyst (usually potassium hydroxide) goes with the glycerol. The ester layer is washed with water at the rate of $28 \%$ by volume of the oil with gentle agitation several times until the washing is neutral to $\mathrm{pH}$ paper or the washing becomes clear. Washing can bea hot mild salt solution or water containing acetic acid, tannic acid or hydrochloric acid. This is used to lessen emulsion formation due to presence of soap and to make separation of water and ester layer easier. After gentle agitation, the solution is allowed to settle. After settling, the aqueous solution is drained. For the final washing, water alone is added at $28 \%$ by volume of oil. Gentle agitation follows and then the solution is allowed to settle before draining the aqueous layer completely (Rehman et al 2009c).

\section{Biodiesel Economics}

Biodiesel fuel is reliable, renewable, biodegradable and non-toxic. It is less harmful to the environment for oils and from waste fats and oils. Because it can be used directly in diesel engines. Biodiesel offers the immediate potential to reduce our demand for petroleum.

Leverage limited supplies of fossil fuels

Regardless of whose perspective we choose to believe on the future of coal, oil, and natural gas. Their supply is, ultimately, limited. Biodiesel can help us leverage our use of these fuels.

\section{Benefit to Domestic Economy}

Spending on foreign imports of petroleum takes dollars away from our economy. Biodiesel can help us shift this spending to domestically produced energy and offers new energy related markets to farmers.

\section{Environmental Effects}

Reduce greenhouse gas emissions

The burning of fossil fuels during the past century has dramatically increased the levels of carbon dioxide (CO2) and other greenhouse gases that trap heat in our atmosphere. The implications are hotly debated, but the levels of these gases have unquestionably risen at unprecedentedratesinthecontextofgeological time. Tothe 
extent thatbiodiesel istrulyrenewable, itcould helpreduce greenhouse gas emissions from the transportation sector.

Reduce air pollution and related public health risks

One of the U.S. Environmental Protection Agency's (EPA) primary charges is to reduce public health risks associated with environmental pollution. Biodiesel can play a role in reducing emissions of many air pollutants, especially in urban areas. Theseincludeparticulatematter (PM), carbon monoxide (CO), hydrocarbons (HC), sulfur oxides (Sox) nitrogen oxides (NOx) and air toxics.

\section{Emissions, Engine Problem and Deposits}

Much research on the use of neat vegetable oils as fuel substitute have already been done and reported. Their properties are competitive with conventional diesel fuel in some emission categories, but problems were also identified for other kinds of emissions. It was shown that poly-aromatic hydrocarbon (PAH) emissions were lower for neat vegetable oils, especially the alkylated PAHs that are common in the emission of conventional diesel fuel (DF). Besides higher NOx levels, aldehydes are reported to present problems with neat vegetable oils. Total aldehyde increases dramatically with vegetable oils and formaldehyde formation is consistently higher than with DF. It has also been reported that component triglycerides (TGs) in vegetable oil can lead to formation of aromatics via acrolein $(\mathrm{CH} 2=\mathrm{CH}-\mathrm{CHO})$ from the glycerin moiety (Pundir 2007).

Most studies report that for short-term trials, neat oils give satisfactory engine performance and power output is often equal to or even slightly better than conventional DF. However, vegetable oils cause engine problems. Studies on sunflower oil, coconut and other oils as fuel noted choking of injector nozzles, sticking piston rings, crankcase oil dilution, lubricating oil contamination and other problems. The causes of these problems are attributed to the polymerization of TGs via their double bonds that leads to formation of engine deposits, as well as the low volatility and high viscosity with resulting poor atomization patterns (Pundir 2007).

\section{Alkyl esters}

Biodiesel emissions are substantially lower than petroleum diesel emissions. Compared to gasoline, biodiesel produces no sulfur dioxide, no net carbon dioxide, up to 20 times less carbon monoxide, and more free oxygen. Table 1 shows the air emission for diesel, B20, and B100.gm/kWh total value of emissions which thrown in the atmosphere, and Table 2 shows the percentage reduction in air emission for diesel, B20, and B100. Biodiesel has the following emission characteristics when compared to petroleum diesel fuel:

- Reduction of net carbon dioxide (CO2) and sulfur dioxide (SO2) emissions by $100 \%$.
- Reduction of soot emissions by $40-60 \%$.

- Reduction of carbon monoxide(CO) and hydrocarbon emissions by $10-50 \%$.

- Reduction of all polycyclic aromatic hydrocarbons (PAHs) and specifically the reduction of the following Carcinogenic PAHs:

- Reduction of phenanthren by $97 \%$.

- Reduction of benzofloroanthen by $56 \%$.

- Reduction of benzapyren by $71 \%$.

- Reduction of aldehydes and aromatic compounds by $13 \%$.

- Reduction orincrease of nitrous oxide(Nox) emissions by $5-10 \%$ depending on the age of the vehicle and the tuning of the engine.

Figure 2 and Figure 3 show the differences in life cycle air emissions for B100 and B20 versus petroleum diesel fuel. Replacing petroleum diesel with biodiesel reduces life cycle air emissions for all the pollutants tracked. The largest reduction (34.5\%) in air emissions that occurs

\begin{tabular}{|l|l|l|l|}
\hline \multicolumn{1}{|c|}{ Pollutant } & $\begin{array}{c}\text { Petroleum } \\
\text { Diesel }\end{array}$ & \multicolumn{1}{|c|}{ B20 } & \multicolumn{1}{c|}{ B100 } \\
\hline $\mathrm{CH}_{4}$ & 0.202839 & 0.201795 & 0.197616 \\
\hline $\mathrm{NOx}$ & 0.006784 & 0.005887 & 0.002297 \\
\hline $\mathrm{CO}$ & 1.26981 & 1.18219 & 0.831723 \\
\hline NMHC & 0.131467 & 0.194075 & 0.44451 \\
\hline Hydrocarbons (unspecified) & 0.249053 & 0.229605 & 0.151814 \\
\hline Benzene & $4.24 \mathrm{E}-05$ & $3.43 \mathrm{E}-05$ & $1.84 \mathrm{E}-06$ \\
\hline Formaldehyde & 0.000568 & 0.000459 & $2.48 \mathrm{E}-05$ \\
\hline PM10 & 0.084094 & 0.076589 & 0.046572 \\
\hline Particulars (unspecified) & 0.130281 & 0.123891 & 0.098329 \\
\hline SOx & 0.926335 & 0.911458 & 0.851949 \\
\hline NOx & 5.00856 & 5.1423 & 5.67728 \\
\hline HCl & 0.003164 & 0.00325 & 0.003593 \\
\hline HF & 0.000396 & 0.000383 & 0.000334 \\
\hline NH ${ }_{3}$ & $3.15 \mathrm{E}-08$ & 0.014694 & 0.073471 \\
\hline
\end{tabular}

Table 1. Air Emission for Diesel, $\mathrm{B}_{20}$, and $\mathrm{B}_{100}$. in gm $/ \mathrm{kwh}$

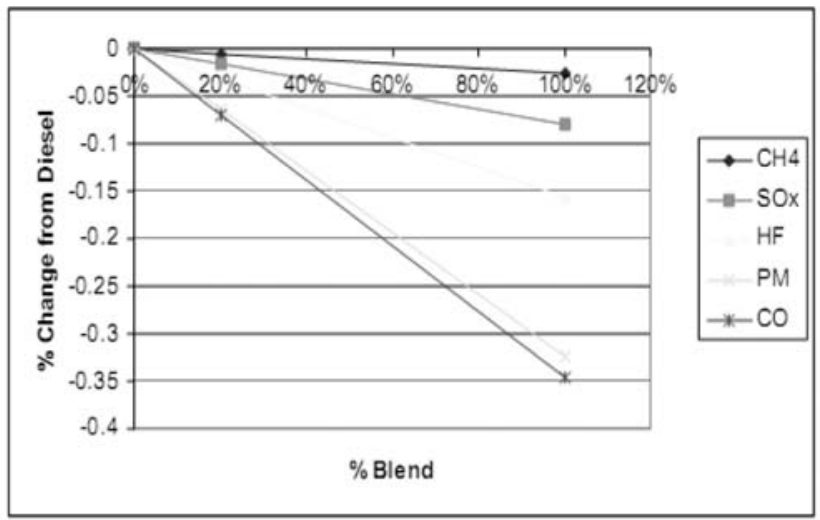

Figure 2. Percentage Reduction in Air Emission for Diesel, B20, and B100 


\begin{tabular}{|c|c|c|}
\hline Pollutant & B20 & B100 \\
\hline $\mathrm{CO}$ & $-6.90 \%$ & $-34.50 \%$ \\
\hline $\mathrm{PM}$ & $-6.48 \%$ & $-32.41 \%$ \\
\hline $\mathrm{HF}$ & $-3.10 \%$ & $-15.51 \%$ \\
\hline $\mathrm{SO}_{\mathrm{x}}$ & $-1.61 \%$ & $-8.03 \%$ \\
\hline $\mathrm{CH}_{4}$ & $-0.51 \%$ & $-2.57 \%$ \\
\hline $\mathrm{NO}_{\mathrm{x}}$ & $2.67 \%$ & $13.35 \%$ \\
\hline $\mathrm{HCl}$ & $2.71 \%$ & $13.54 \%$ \\
\hline $\mathrm{HC}$ & $7.19 \%$ & $35.96 \%$ \\
\hline
\end{tabular}

Table 2. Percentage Reduction of Emission for Biodiesel Blends

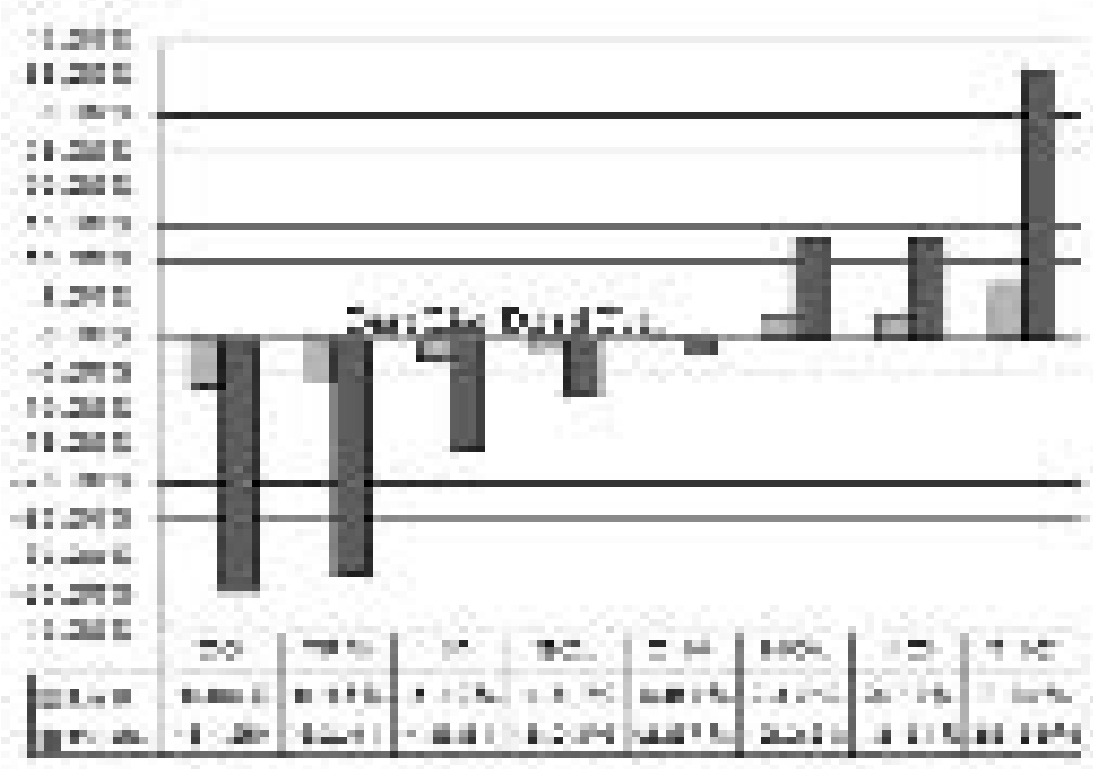

Figure 3. Percentage Reduction in Air Emission for Diesel, B20, and B100
CO2 emissions. At the tailpipe, biodiesel (most of which is renewable) emits $4.7 \%$ more $\mathrm{CO} 2$ than petroleum diesel. The nonrenewable portion comes from the methanol. Biodiesel generates $573.96 \mathrm{~g} / \mathrm{bhp}$-h compared to $548.02 . \mathrm{g} / \mathrm{bhp}$-h for petroleum diesel. The higher $\mathrm{CO}_{2}$ levels result from combustion that is more complete and the concomitant reductions in other carbon-containing tailpipe emissions. As Figure 3 shows, the overall life cycle emissions of $\mathrm{CO} 2$ from B100 are $78.45 \%$ lower than those of petroleum diesel. The reduction is a direct result of carbon recycling in soybean plants. B20 reduces net CO2 emissions by $15.66 \%$

Figure 5 summarize $\mathrm{CO} 2$ flows from the total life cycles of biodiesel and petroleum diesel and the total $\mathrm{CO} 2$ released at the tailpipe for each fuel. The dominant source of $\mathrm{CO} 2$ for both the petroleum diesel and the biodiesel life cycles is the combustion of fuel in the bus. For petroleum diesel, $\mathrm{CO} 2$ emitted from the tailpipe represents $86.54 \%$ of the total $\mathrm{CO} 2$ emitted across the entire life cycle of the fuel. Most remaining $\mathrm{CO} 2$ comes from emissions at the oil refinery, which contribute $9.6 \%$ of the total $\mathrm{CO} 2$ emissions. For biodiesel, $84.43 \%$ of the $\mathrm{CO} 2$ emissions occur at the tailpipe. The remaining $\mathrm{CO} 2$ comes almost equally from soybean agriculture, soybean crushing, and soy oil conversion to biodiesel.

when B100 or B20 is used as a substitute for petroleum diesel is for $\mathrm{CO}$. The effectiveness of B20 in reducing life cycle emissions of $\mathrm{CO}$ drops proportionately with the blend level. Biodiesel could, therefore, effectively reduce $\mathrm{CO}$ emissions in CO non-attainment areas B100 exhibits life cycle TPM emissions that are $32.41 \%$ lower than those of the petroleum diesel life cycle. As with $\mathrm{CO}$, the effectiveness of biodiesel in reducing TPM drops proportionately with blend level. This is a direct result of reductions in PM10 at the tailpipe, which are $68 \%$ lower for B100 versus petroleum diesel. PM10 emitted from mobile sources is a major EPA target because of its role in respiratory disease. Urban areas represent the greatest risk in terms of numbers of people exposed and levels of PM10. Using biodiesel in transportation may be an option for controlling life cycle emissions of TPM and tailpipe emissions of PM10.

Figure 4 shows the effect of biodiesel blend levels on

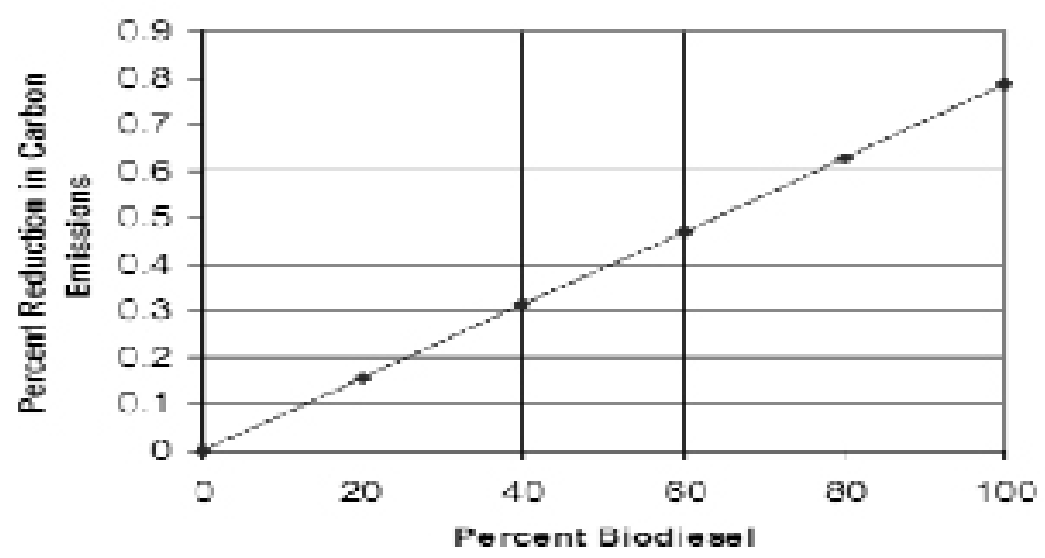

Figure 4. Effect of Biodiesel Blend Level on CO2 Emissions

\section{Conclusions}

Energy balance

Biodiesel and petroleum diesel haveverysimilarenergy efficiencies. The base-case model estimates life cycle energy efficiencies of $80.55 \%$ for biodiesel versus $83.28 \%$ for petroleum diesel. The lower efficiency for biodiesel reflects slightly higher process energy requirements for 
converting the energy contained in soybean oil to fuel. In terms of effective use of fossil energy resources, biodiesel yields around 3.2 units of fuel product energy for every unit of fossil energy consumed in thelifecycle. Bycontrast,

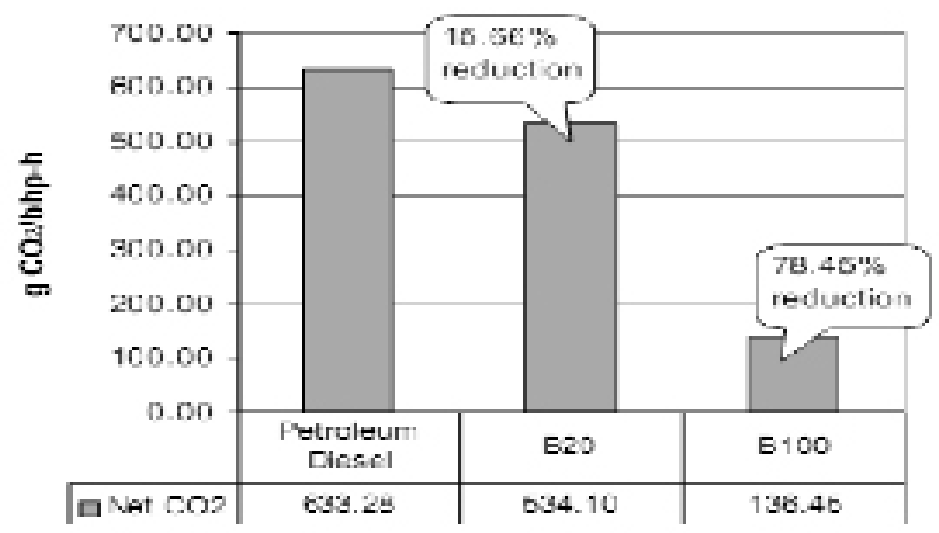

Figure 5. Comparisons of CO2 life Cycle Emission for Diesel \&Biodiesel
Total Hydrocarbons

We also report 35\% higher life cycle emissions of THC compared to petroleum diesel, but tailpipe THCemissions are 37\% lower for B100 than for petroleum diesel. The increase results from hexane being released during soybean processing and to volatilization of agrochemicals applied on the farm. We have less

\section{Summary}

Biodiesel (fatty acid alkyl ester) is a cleanerburning diesel replacement fuel made from natural, renewable and biodegradable sources. It is a stable diesel, which performs reliably in all diesel engines without any modification, is mixable with petroleum diesel fuel, easy to make and safe to handle. Biodiesel cuts emissions, reduce particulates, unburned hydrocarbons, carbon monoxide and carbon dioxide. It is petroleum diesel life cycle yields only 0.83 units of fuel product energy per unit of fossil energy consumed. Such measures confirm the renewable nature of biodiesel. The life cycle for B20 has a proportionately lower fossil energy ratio (0.98 units of fuel product energy for every unit of fossil energy consumed). B2oís fossil energy ratio reflects the impact of adding petroleum diesel into the blend.

\section{Carbon Dioxide Emissions}

The demand for fossil energy associated with biodiesel is low, so its life cycle emissions of $\mathrm{CO} 2$ are, not surprisingly, much lower. Per unit of work delivered by an engine, B100 reduces net CO2 emissions by $78.45 \%$ compared to petroleum diesel. B20ís life cycle $\mathrm{CO} 2$ emissions are $15.66 \%$ lower. Thus, replacing petroleum diesel with biodiesel in urban buses is an extremely effective strategy for reducing $\mathrm{CO} 2$ emissions.

\section{Total Particulate Matter and Carbon Monoxide Emissions}

The B100 life cycle produces 32\% less TPM and $35 \%$ less CO than the petroleum diesel life cycle. Most occur because of lower emissions at the tailpipe. PM10 emissions from an urban bus operating on biodiesel are $68 \%$ lower than those from an urban bus operating on petroleum diesel. Biodiesel reduces tailpipe CO emissions by $46 \%$.

\section{Nitrogen Oxide Emissions}

At the same time, NOx emissions are 13\% higher for the B100 life cycle compared to the petroleum diesel life cycle. B20 has $2.67 \%$ higher life cycle emissions of NOx. Again, this increase is attributed to higher NOx emissions at the tailpipe. An urban bus run on B100 has NOx emissions that are 8.89\% higher than a bus operated on petroleum diesel. practically free from lead, sulfur and halogens. Biodiesel, therefore, is a very promising alternative fuel that can lead to a cleaner environment.

Rajesh Kumar Pandey, is a Senior research fellow in the department of Mechanical Engineering, M.A. National Institute of Technology (MANIT), Bhopal, India, working in the field of Engine research over the years. He has more than 12 years of teaching experience at graduate and post graduate level, published 30 research papers in reputed journal and proceedings.

Corresponding address: email: rkpmanit@gmail. com

A. Rehman, $\mathrm{PhD}$, is a Assistant Professor of Mechanical Engineering at MANIT, Bhopal, India and has more than 22 years of teaching experience at graduate and post graduate levels in Indian universities and published more than 50 research papers in reputed journals and proceedings. He is actively involved in research activities on I.C. Engines and in environmental science, and has guided a number of $\mathrm{M}$. Tech and $\mathrm{PhD}$ candidates towards their degrees.

Corresponding address: manit1963@yahoo.com

R. M. Sarviya $\mathrm{PhD}$, is a Assistant Professor of Mechanical Engineering at MANIT, Bhopal, India and has more than 22 years of teaching experience at graduate and post graduate levels in Indian universities and published more than 50 research papers in reputed journals and proceedings. He is actively involved in research activities in Heat Transfer, I.C. Engines and in environmental science, and has guided a number of $\mathrm{M}$. Tech and $\mathrm{PhD}$ candidates towards their degrees.

Corresponding address: rmsarviya@rediffmail.com

Savita Dixit, $\mathrm{PhD}$, is an Assistant Professor of Applied Chemistry in MANIT, National Institute of Technology at 
Bhopal, India, and has more than 20 years of teaching experience at graduate and post graduate levels in Indian universities. She is actively involved in research activities in environmental sciences. She has also guided $\mathrm{PhD}$ and $\mathrm{M}$. Tech. candidates towards their degrees.

Corresponding address: savitadixit1@yahoo.com

\section{References}

Agarwal, Avinash, 2006, 'Biofuel application as fuel for IC engines', J ournal of Progress in Energy and Combustion Sciences v.33, pp.233-271.

Pramanik, K., 2003, 'Property and use of jatropha oil and diesel fuel in CI engine,' International J ournal of Renewable Energy v.28, pp.239-248.

Puhan, Sukumar, N. Vedaraman, V.B. Ram Boppana, G. Sankarnarayanan and K. J eychandran, 2005, 'Mahua oil (Madhuca indica seed oil) methyl ester as biodieselpreparation and emission characteristics, Biomass and Bioenergy v.28, pp.87-93.

Pundir, B.P., 2007, Engine Emissions, New Delhi: Narosa Publishing House.

Ramesh, A. and M.Senthil Kumar, 2003, 'An experimental comparison of methods to use methanol and jatropha oil in a CI engine', International J ournal of
Renewable Energy v.25, pp.309-318.

Rehman , A., R.M. Sarviya, S. Dixit and R.K. Pandey, 2009a, 'Developmentofcleanburningfuelforcompression ignition engine', Asian J ournal of Experimental Sciences v.23, n.1, pp.223-234.

Rehman , A., R.M. Sarviya, S. Dixit and R.K. Pandey, 2009b. 'Effect of injection parameter on diesel engine emission fueled with karanja oil, International J ournal of Environmental Research v.3, n.3, pp.195-198.

Rehman , A., R.M. Sarviya, S. Dixit and R.K. Pandey, 2009c. 'Influence of air:fuel quality on performance and emission characteristics of C.I.engine, International J ournal of Pollution Research v. 28, n.2, pp.463-470.

Rehman, A. and K.C. Singhai, 1995, Vegetable oils as alternate fuels for diesel engines', pp 924-928 in Proceedings of Fourth Asia Pacific International Symposium on Combustion and Energy Utilization, Hong Kong: APISCEU.

Usta, N., 2005, 'Use of tobacco seed oil methyl ester in a turbocharged indirect injection diesel engine, Biomass and Bioenergy v.28, pp.77-86.

other than limited link transmission lines (which can be fixed on the size of the project)

7. Establishment of Cross Border Transmission Lines

8. Review of PPA Rate and Electricity Tariff

Review and revision of power purchase rates and Electricity Tariff of NEA periodically with respect to prevailing bank interest rates and market price of materials and wages.

9. Exemption of Tax, VAT etc.

- Exemption of VAT and Taxes on construction materials

10. Approval after timely review of the proposed Electricity Act \&Nepal Electricity Regulatory Commission Act from the Parliament and implement at the earliest.

11. Simplify procedures of procurement, importation, transportation, storage and handling of explosives for hydropower construction works.

12. Prepare a roster of Experts in the field of hydropower, electro- mechanical, hydro- mechanical, power transmission, geology, roads, construction management, tender documents, variations \& claims, dispute resolution and financial analyst.

13. Createa team of Panel of Experts for hydro power development who will advisethegovernmentfor selecting, developing, implementing and TROUBLE SHOOTING hydro power projects, as and when required. 